\title{
Peningkatan Keterampilan Pembelajaran Melalui Pendekatan Saintifik Berbasis Lesson Study di Program Studi Pendidikan Biologi
}

\author{
Agus Purwanto \\ Program Studi Pendidikan Biologi, Universitas Veteran Bangun Nusantara Sukoharjo \\ *Alamat email koresponden: purwantoaguss183@gmail.com
}

\begin{abstract}
Abstrak
Kualitas siswa dalam Program Pendidikan Biologi Universitas Veteran Bangun Nusantara tidak dalam kualitas tertinggi. Tetapi kompetensi kelulusan standar diperlukan di tingkat yang baik. Oleh karena itu, diperlukan peningkatan keterampilan dalam kegiatan belajar. Peningkatan aktivitas pembelajaran telah dilakukan melalui pendekatan saintifik berbasis lesson study pada mata kuliah sistematika tumbuhan tinggi melalui 4 siklus. Setiap siklus memiliki tahapan perencanaan-lihat-lihat. Data diperoleh dari deskripsi tahapan plan-do-see dan analisis dilakukan secara kualitatif. Hasil penelitian ini menunjukkan bahwa implementasi rencana itu layak dan teliti. Implementasi do bahwa perkuliahan dapat mengatur waktu dengan baik, memberikan motivasi dan ketepatan pada kesalahpahaman yang disampaikan oleh mahasiswa; selain itu, aktivitas belajar siswa dan kemandirian mereka selama kegiatan belajar semakin meningkat. Implementasi see dapat meningkatkan kolaborasi antar dosen dalam menyusun rencana selanjutnya. Studi ini menyimpulkan bahwa penerapan pendekatan ilmiah berdasarkan studi pelajaran dapat meningkatkan keterampilan dosen dalam melakukan kegiatan belajar siswa, meningkatkan kegiatan belajar siswa dan meningkatkan kemandirian siswa.
\end{abstract}

Kata kunci: keterampilan belajar, lesson study, pendekatan saintifik

\section{Improving Learning Ability Through Scientific Learning Based on Lesson Study in the Biology Education Departement}

\author{
Agus Purwanto \\ Biology Education Departement, Universitas Veteran Bangun Nusantara Sukoharjo \\ *Correspondent's email address: purwantoaguss183@gmail.com
}

\begin{abstract}
The quality of students in Biology Education Program of Veteran Bangun Nusantara University is not in the highest one. But the standard graduation competence is required in good level. Therefore, improving skill on learning activiy is needed. Improved learning activity has done through scientific approach based on lesson study in High Systematic Plant subject through 4 cycles. Each cycles have plan-do-see stages. Data is obtained from the description of plan-do-see stages and the analysis is carried out qualitatively. Result of this research shows that the implementation of plan is decent and meticulous. The implementation of do evinces that lecture can manage time properly, give motivation and precise on misconception presented by students; besides, the students' learning activity and their independence during learning activities are increasingly better. The implementation of see can improve collaboration among lecturer on constructing the next plan. This study concludes that the implementation of scientific approach based on lesson study can improve lecturer's skill in performing students' learning activity, improve students' learning activity and promote students' independence.
\end{abstract}

Keywords: learning skill, lesson study, scientific approach, 


\section{PENDAHULUAN}

\section{Universitas Veteran Bangun}

Nusantara Sukoharjo adalah perguruan tinggi swasta berlokasi di dekat perguruan tinggi negeri besar. Hal tersebut mengindikasikan bahwa mahasiswanya merupakan limpahan dari mahasiswa yang tidak diterima di perguruan tinggi negeri, termasuk di dalamnya adalah mahasiswa program studi Pendidikan Biologi. Berarti kualitas mahasiswanya kelas dua. Namun mutu kompetensi kelulusannya dituntut baik. Untuk itu, dibutuhkan peningkatan keterampilan dalam proses pembelajaran.

Di dalam peraturan pemerintah No. 19 tahun 2005 tentang Standar Nasional Pendidikan, Bab IV pasal 19 ayat 1 dinyatakan bahwa proses pembelajaran pada satuan pendidikan diselenggarakan secara interaktif, inspiratif, menyenangkan, menantang, memotivasi siswa untuk berpartisipasi aktif serta memberikan ruang yang cukup bagi prakarsa, kreativitas, dan kemandirian sesuai bakat, minat, dan perkembangan fisik serta psikologi siswa. Pendekatan pembelajaran ilmiah (scientific teaching) merupakan bagian dari pendekatanpedagogis pada pelaksanaan pembelajaran dalam kelas yang melandasai penerapan metode ilmiah.Penggunaan Pendekatan saintifik dalam pembelajaran harus dipandu dengan kaida-kaidah pendekatan ilmiah. Pendekatan ini bercirikan penonjolan dimensi pengamatan, penalaran, penemuan, pengabsahan, dan penjelasan tentang suatu kebenaran. Penerapan pendekatan saintifik dalam pembelajaran melibatkan ketrampilan proses seperti mengamati, mengklasifikasi, mengukur, meramalkan, menjelaskan, dan menyimpulkan.Dengan demikian, proses pembelajaran harus 2 dilaksanakan dengan dipandu nilai-nilai, prinsip-prinsip, atau kriteria ilmiah. (Sudrajat, 2013).

Lesson study merupakan salah satu bentuk pembinaan guru (in-service) yang dapat dilakukan untuk meningkatkan proses pembelajaran dan profesionalisme guru. Lesson study bukan merupakan suatu strategi atau metode pembelajaran, tetapi kegiatan lesson study dapat menerapkan berbagai strategi dan metode pembelajaran yang dapat disesuaikan dengan situasi dan kondisi serta permasalahan yang dihadapi pendidik pada setiap proses pembelajaran (Khaeriyah dkk, 2011). Pada pelaksanaan lesson study, dosen bekerja sama dalam suatu kelompok yang meliputi perencanaan, praktik mengajar, obervasi, refleksi atau kritikan terhadap pembelajaran. Dengan lesson study para guru dapat leluasa meningkatkan kinerja dan keprofesio-nalannya yang akhirnya dapat meningkatkan mutu pembelajaran dan meghasilkan siswa yang berkualitas tinggi. Mulyana (2007) memberikan rumusan tentang Lesson Study sebagai salah satu model pembinaan profesi pendidik melalui pengkajian pembelajaran secara kolaboratif dan berkelanjutan berlandaskan pada prinsip-psrinsip kolegalitas dan mutual learning untuk membangun komunitas belajar. Menurut Cerbin \& Kopp, (2006) Masing-masing guru dapat merenungkan dan meningkatkan praktek mereka dalam kelas mereka sendiri. Kompleksitas pekerjaan sehari-hari jarang memungkinkan mereka untuk berkomunikasi dengan rekan-rekan tentang apa yang mereka temukan tentang pengajaran dan pembelajaran

Pembelajaran merupakan suatu proses yang kompleks dan melibatkan 
berbagai aspek yang saling berkaitan. Pembelajaran terjadi pada saat berlangsungnya interaksi antara guru dengan siswa untuk mencapai tujuan pembelajaran. Sebagai suatu proses, sudah pasti suatu pembelajaran akan meliputi kegiatan yang dilakukan oleh guru mulai dari perencanaan, membuka (pendahuluan) sampai melaksanakan rencana pembelajaran (kegiatan inti) dan akhirnya menutup pelajaran (kegiatan akhir). Oleh karena itu untuk menciptakan pembelajaran yang kreatif dan menyenangkan, diperlukan berbagai keterampilan, di antaranya adalah keterampilan dalam pelaksanaan pembelajaran. Keterampilan pembelajaran merupakan kompetensi profesional yang cukup kompleks sebagai integrasi dari berbagai kompetensi guru secara utuh dan menyeluruh agar tercipta pembelajaran yang kreatif, profesional, dan menyenangkan. Berhasil atau tidaknya pembelajaran tergantung pada guru, yang memiliki peranan memberikan pengetahuan, sikap, nilai dan keterampilan guru (Suparman, 2005).

Permasalahan yang diangkat, adalah: apakah terdapat peningkatan keterampilan pembelajaran dosen dalam mendorong siswa belajar serta meningkatkan mahasiswa agar lebih aktif dan mandiri belajar melalui pendekatan saintifik berbasis lesson study. Tujuan dalam kegiatan ini adalah untuk meningkatkan keterampilan pembelajaran dosen dalam mendorong siswa belajar serta meningkatkan mahasiswa agar lebih aktif dan mandiri belajar melalui pendekatan saintifik berbasis lesson study.

\section{METODE}

Implementasi model menggunakan lesson study dengan skema sebagai berikut.

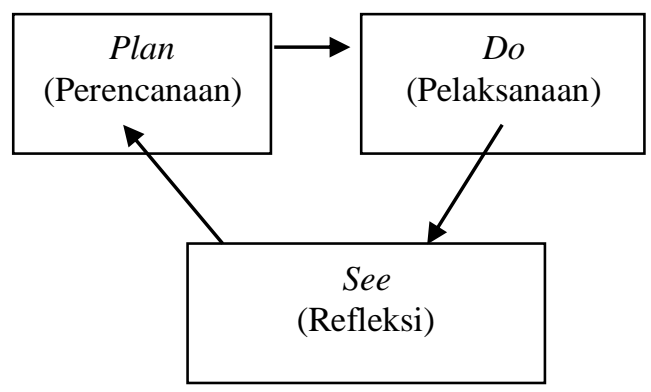

Gambar 1. Bagan Pelaksanaan Lesson Study

Tahap perencanaan dosen yang tergabung dalam lesson study secara kolaboratif menyusun RMP yang berpusat kepada peserta didik. Perencanaan berawal dari analisis terhadap kebutuhan dan permasalahan yang dihadapi dalam pembelajaran, seperti: kompetensi dasar, cara membelajarkan mahasiswa, menyiasati kekurangan fasilitas belajar, dan secara kolaboratif juga dosen mencari solusi dalam memecahkan permasalahan yang ditemukan tersebut. Dari hasil analisis dosen tersebut diharapkan menjadi bahan pertimbangan dalam penyusunan RMP untuk diterapkan pada proses pembelajaran.

Tahap pelaksanaan ada dua kegiatan yakni kegiatan pelaksanaan pembelajaran yang dilakukan oleh salah seorang dosen yang disepakati atau atas permintaan sendiri untuk mempraktikan RMP yang telah disusun bersama dan kegiatan observasi yang dilakukan oleh dosen yang bertindak sebagai observer atau pengamat.

Tahap refleksi dilakukan dalam bentuk diskusi yang diikuti oleh seluruh peserta lesson study yang dipandu oleh seorang ketua. Diskusi dimulai dari 
penyampaian kesan-kesan guru yang telah mempraktikan pembelajaran. Selanjutnya, semua pengamat menyampaikan tanggapan atau saran secara bijak terhadap proses pembelajaran yang telah dilaksanakan yang didukung oleh bukti-bukti yang diperoleh dari hasil pengamatan, tidak berdasarkan opininya sendiri. Hal ini dilakukan sebagai upaya untuk perbaikan proses pembelajaran kedepannya.

Subjek dalam penelitian ini adalah tim lesson study dosen biologi sebanyak 4 orang yang terdiri atas sarjana biologi 2 orang (di antaranya dosen model), master sains satu orang dan master pendidikan 1 orang. Mahasiswa pendidikan biologi semester IV sebanyak 27 mahasiswa terdiri atas perempuan 20 orang dan 7 mahasiswa laki-laki. Teknik pengumpulan data dengan pengamatan langsung dari pelaksanaan plan-do-see. Intrumen berupa lembar observasi, dengan indikator antara lain aktivitas dosen, hasil karya dosen (RPP, catatan refleksi), aktivitas belajar mahasiswa, sikap kemandirian siswa.

Data yang berkaitan dengan pengembangan profesional dianalisis menggunakan diskriptif kualitatif, dari aktivitas dan karya dosen dalam melaksanakan tahapan plan-do-see. Sedangkan data yang diperoleh dari aktivitas dan kemandirian mahasiswa dianalisis secara ddeskriptif kualitatif dari hasil perpaduan antara hasil refleksi observer dan pengamatan langsung.

\section{HASIL DAN PEMBAHASAN}

\section{Siklus Pertama}

Perencanaan (plan) diselenggarakan oleh Tim terdiri atas 4 dosen (1 dosen model, 1 ketua, dan 2 anggota) secara bersama-sama meninjau silabus dan RMP matakuliah Sistematika Tumbuhan Tinggi. Perangkat pembelajaran ini sudah disiapkan oleh dosen model, kemudian dicermati bersama. Hasil pengamatan, silabus sudah dapat diterima oleh tim, sedangkan RMP yang masih perlu ditambahkan meliputi tujuan pembelajaran; tahap eksplorasi, elaborasi, dan konfirmasi; kharakter belajar; materi ajar dijabarkan; serta penilaian berupa aktivitas dan kemandirian mahasiswa baik perorangan maupun kelompok.

Pelaksanaan (Do) terdiri dari tahap eksplorasi, elaborasi dan konfirmasi. Pada Tahap eksplorasi, persiapan meliputi dosen menugaskan pada kelompok 1 untuk menyiapkan materi subkelas Apetalay seminggu sebelum tahap do. Pelaksanaan meliputi kegiatan kelompok 1 membuat hasil diskusi materi berupa ringkasan materi, slide power point, dan menyiapkan 10 soal untuk bahan diskusi antar kelompok. Tahap Elaborasi yaitu kegiatan presentasi, kelompok 1 mempresentasikan materi subkelas Apetalay dengan alokasi waktu 20 menit. Diskusi Antarkelompok berisi kegiatan pertanyaan bahan diskusi diberikan kepada 3 kelompok oleh kelompok yang berpresentasi dengan alokasi waktu 60 menit. Pada open 1 ini hanya berhasil didiskusikan 4 pertanyaan. Masing-masing kelompok sebelum menjawab pertanyaan diberi waktu 3 menit untuk mengadakan kolaborasi antar anggota kelompok dengan tujuan tercipta kerja sama. Semua kelompok aktif dalam diskusi. Hasil diskusi ditulis di papan tulis agar dapat dicermati bersama. Proses diskusi ini dipandu oleh seorang moderator dari kelompok presentasi. Tahap konfirmasi meliputi kegiatan dosen 
meluruskan konsep yang belum benar. Dari soal maupun jawaban yang didiskusikan ada yang bersifat taksonomis dan nontaksonomis.

Kegiatan refleksi (See) diikuti oleh 4 observer dan 1 dosen model. Hasil refleksi menyimpulkan bahwa aktivitas dan kemandirian mahasiswa sudah tampak, karena ada kolaborasi yang baik antaranggota kelompok, masih ditemukan beberapa miskonsepsi materi baik pada saat presentasi maupun diskusi, alokasi waktu pada pelaksanaan (do) sudah sesuai dengan RMP.

\section{Siklus Kedua}

Perencanaan (plan) oleh Tim terdiri atas 5 dosen (1 dosen model, 1 ketua, 2 anggota, dan 1 dosen monitoring) secara bersama-sama meninjau RMP. Hasil diskusi adalah meliputi tentang indikator yang harus jelas, jika indikator belum jelas dapat dijabarkan pada tujuan pembelajaran.

Pelaksanaan (Do) pada tahap eksplorasi berisi persiapan dosen menugaskan pada kelompok 2 untuk menyiapkan materi subkelas Dialypetalae seminggu sebelum DO. Tahap pelaksanaan berisi kegiatan kelompok 2 membuat hasil diskusi materi berupa ringkasan materi, slide power point, dan menyiapkan 10 soal untuk bahan diskusi antarkelompok. Tahap elaborasi berisi kegiatan presentasi yaitu kelompok 2 mempresentasikan materi subkelas Dialypetalaedengan alokasi waktu 20 menit. Kegiatan selanjutnya diskusi antarkelompok yaitu pertanyaan bahan diskusi diberikan kepada 3 kelompok oleh kelompok yang berpresentasi dengan alokasi waktu 60 menit. Pada open 2 ini sudah berhasil didiskusikan 6 pertanyaan. Masing-masing kelompok sebelum menjawab pertanyaan diberi waktu 3 menit untuk mengadakan kolaborasi antar anggota kelompok dengan tujuan tercipta kerja sama. Semua kelompok aktif dalam diskusi. Hasil diskusi ditulis di papan tulis agar dapat dicermati bersama. Proses diskusi ini dipandu oleh seorang moderator dari kelompok presentasi. Selanjutnya konfirmasi berisi kegiatan dosen meluruskan konsep yang belum benar. Dari soal maupun jawaban yang didiskusikan ada yang bersifat taksonomis dan nontaksonomis.

Kegiatan terakhir adalah refleksi (See). Refleksi yang diikuti oleh 4 observer dan 1 dosen model. Hasil refleksi menyimpulkan bahwa mahasiswa terkesan lebih siap dalam melakukan pembelajaran, diskusi terkesan hidup, namun masih ada miskonsepsi, alokasi waktu sesuai dengan RMP.

\section{Siklus Ketiga}

Tahap perencanaan (plan) dilakukan oleh Tim terdiri atas 5 dosen (1 dosen model, 1 ketua, 2 anggota, dan 1 dosen monitoring) secara bersama-sama meninjau RMP. Pada diskusi perencanaan tim sepakat bahwa RMP sudah dapat digunakan untuk pembelajaran.

Tahap pelaksanaan (do) diawali dengan eksplorasi. Kegiatan pertama pada eksplorasi adalah persiapan dosen menugaskan pada kelompok 3 untuk menyiapkan materi subkelas Sympetalae. Kegiatan pelaksanaan yaitu kelompok 3 membuat hasil diskusi materi berupa ringkasan materi, slide power point, dan menyiapkan 10 soal untuk bahan diskusi antar kelompok. Selanjutnya elaborasi berisi presentasi kelompok 3 dengan materi subkelas Sympetalay dengan alokasi waktu 20 menit. Diskusi antar kelompok 
berisi kegiatan pertanyaan bahan diskusi diberikan kepada 3 kelompok oleh kelompok yang berpresentasi dengan alokasi waktu 60 menit. Pada open 3 ini lebih banyak pertanyaan yang didiskusikan, yaitu 7 pertanyaan. Masingmasing kelompok sebelum menjawab pertanyaan diberi waktu 3 menit untuk mengadakan kolaborasi antar anggota kelompok dengan tujuan tercipta kerja sama. Semua kelompok aktif dalam diskusi. Hasil diskusi ditulis di papan tulis agar dapat dicermati bersama. Proses diskusi ini dipandu oleh seorang moderator dari kelompok presentasi. Kegiatan konfirmasi berisi kegiatan dosen meluruskan konsep yang belum benar. Dari soal maupun jawaban yang didiskusikan ada yang bersifat taksonomis dan nontaksonomis.

Tahap refleksi (see) diikuti oleh 4 observer dan 1 dosen model. Hasil refleksi menyimpulkan bahwa aktivitas dan kemandirian mahasiswa semakin nampak, masih ditemukan miskonsepsi materi, plan yang sudah direncanakan telah dilaksanakan dengan baik.

\section{Siklus Keempat}

Perencanaan (plan) diselenggarakan oleh. Tim terdiri atas 5 dosen (1 dosen model, 1 ketua, 2 anggota, dan 1 dosen monitoring) secara bersama-sama meninjau RMP. Pada diskusi perencanaan tim sepakat bahwa RMP sudah sesuai dengan yang diharapkan.

Tahap pelaksanaan (Do) meliputi eksplorasi berisi persiapan dosen menugaskan pada kelompok 4 untuk menyiapkan materi Kelas Monocotyledoneae. Kegiatan pelaksanaan berisi kelompok 4 membuat hasil diskusi materi berupa ringkasan materi, slide power point, dan menyiapkan 10 soal untuk bahan diskusi antar kelompok. Kegiatan elaborasi berisi presentasi dari kelompok 4 dengan materi Kelas Monocotyledoneae dengan alokasi waktu 20 menit. Selanjutnya diskusi antar kelompok berisi pertanyaan bahan diskusi diberikan kepada 3 kelompok oleh kelompok yang berpresentasi dengan alokasi waktu 60 menit. Pada open 4 ini hanya 5 pertanyaan yang dapat didiskusikan. Masing-masing kelompok sebelum menjawab pertanyaan diberi waktu 3 menit untuk mengadakan kolaborasi antar anggota kelompok dengan tujuan tercipta kerja sama. Semua kelompok aktif dalam diskusi. Hasil diskusi ditulis di papan tulis agar dapat dicermati bersama. Proses diskusi ini dipandu oleh seorang moderator dari kelompok presentasi. Selanjutnya kegiatan konfirmasi yaitu dosen meluruskan konsep yang belum benar. Dari soal maupun jawaban yang didiskusikan ada yang bersifat taksonomis dan nontaksonomis.

Tahap refleksi (see) diikuti oleh 6 observer dan 1 dosen model. Hasil refleksi menyimpulkan bahwa mahasiswa nampak semangat dalam diskusi dan masingmasing individu menunjukkan kemandiriannya, masih terjadi miskonsepsi materi,

Hasil yang didapat bahwa pelaksanaan plan semakin baik dan cermat. Ini sesuai yang pendapat Mukhtar (2013) bahwa Lesson Study merupakan salah satu model pembinaan profesi pendidik melalui pengkajian pembelajaran secara kolaboratif dan berkelanjutan berlandaskan pada prinsip-prinsip kolegalitas dan mutual learning untuk membangun komunitas belajar. Yang mempunyai iri-ciri adanya: 
(a) tujuan bersama untuk jangka panjang;

(b) materi pelajaran yang penting; (c) studi tentang siswa secara cermat; dan (d) observasi pembelajaran secara langsung

Pelaksanaan do dosen semakin bisa mengontrol waktu, memberi motivasi, mencermati miskonsepsi yang disampaikan mahasiswa; sedangkan pada mahasiswa aktivitas belajar dan kemandiriannya semakin tampak. Mukhan (2013) mengungkapkan pembelajaran berbasis pendekatan ilmiah mempunyai hasil yang lebih efektif bila dibandingkan dengan penggunaan pembelajaran dengan pendekatan tradidional. pada pembelajaran tradisional, retensi informasi dari guru sebesar $10 \%$ setelah 15 menit dan perolehan pemahaman kontekstual sebesar $25 \%$. Pada pembelajaran berbasisi pendekatan ilmiah retensi informasi dan guru sebesar $90 \%$ setelah dua hari dan perolehan pemahaman kontekstual sebesar $50-70 \%$. Secara individual, hal ini diyakini dapat menumbuhkan semangat introspeksi terhadap apa yang sudah dilakukan selama ini dalam proses pembelajarannya. Sehingga paradig-ma guru yang hanya mentransfer pengetahuan yang dimiliki menjadi memberikan inspirasi kepada siswa untuk berkreasi dan melatih siswa untuk hidup mandiri.

Apabila dalam diri siswa tidak ada perhatian terhadap pelajaran yang dipelajari, maka siswa tersebut perlu dibangkitkan perhatiannya. Dalam proses pembelajaran, perhatian merupakan faktor yang besar pengaruhnya, kalau peserta didik mempunyai perhatian yang besar mengenai apa yang dipelajari peserta didik dapat menerima dan memilih stimuli yang relevan untuk diproses lebih lanjut di antara sekian banyak stimuli yang datang dari luar. Perhatian dapat membuat peserta didik untuk mengarahkan diri pada tugas yang akan diberikan; melihat masalahmasalah yang akan diberikan; memilih dan memberikan fokus pada masalah yang harus diselesaikan.

Pelaksanaan see semakin dapat meningkatkan kolaborasi antar-dosen dalam penyusunan plan berikutnya. Refleksi didapat dari hasil observasi dari observer yang dikolaborasikan sebagai acuan plan siklus berikutnya. Sehingga pelakasanaan siklus berikutnya akan lebih baik. Di samping itu untuk observer dapat mengambil sebagai pengalaman dalam memecahkan masalah pembelajaran.

\section{KESIMPULAN DAN SARAN}

Melalui pendekatan pembelajaran saintifik berbasis lesson study dapat meningkatkan keterampilan pembelajaran dosen dalam membuat mahasiswa belajar. Melalui pendekatan pembelajaran saintifik berbasis lesson study dapat meningkatkan aktivitas dan kemandirian belajar mahasiswa.

Saran peneliti antara lain kepada dosen untuk meningkatkan keterampilan pembelajaran lewat lesson study agar mahasiswa aktivitas dan kemandirian belajarnya dapat meningkat. Kepada Pimpinan perguruan tinggi untuk dapat memprogramkan pelaksanaan lesson study dalam rangka meningkatkan pembelajaran. Kepada kementrian kependidikan untuk lebih ditingkatkan sosialisasi pelaksanaan lesson study.

\section{DAFTAR PUSTAKA}

Atwi, S.M. (2005). Pekerti Mengajar di Perguruan Tinggi Desain Instruksional. Jakarta: Direktorat Jenderal Pendidikan Tinggi. 
Cerbin, W.\& Kopp, B. (2006). Lesson Study as a model for building pedagogical knowledge and improving teaching. International Journal of Teaching and Learning in Higher Education,18(3), 250-257.

Khaeriyah, S., Shofiyati, Maliku, A., \& Yetty, D. (2011). Implementasi Lesson Studi Menerapkan Model STAD untuk Meningkatkan Interaksi. Eksplorasi, dan Motivasi Siswa Pada Bahasa Dispersi di Kelas XII IPA SMA Negeri 1 Pontianak. Jurnal Pendidikan Matematika dan IPA, 2(2), 1-11.

Mukhan, S. (2013). Karakteristik Pendekatan Scientific (Ilmiah) dalam Kurikulum 2013 dalam

http://penelitiantindakankelas.blogspot.com (diakses 21 Nopember 2013).

Mukhtar, A. R. (2013). Keistimewaan dan Tantangan Lesson Study. Jakarta: Badan Litbang \& Diklat Kementrian Agama RI

Mulyana, S. (2007). Lesson Study (Makalah). Kuningan: LPMP-Jawa Barat

Sudrajat, A. (2013). Pendekatan Saintifik/Ilmiah dalam Proses Pembelajaran dalam http://akhmadsudrajat.wordpress.com (diakses 21 Nopember 2013) 